\title{
Comparative analysis of fetomaternal outcome in antenatal women infected with pulmonary and extrapulmonary tuberculosis
}

\author{
Preeti Frank Lewis ${ }^{1}$, Amita Shankarrao Budhewar ${ }^{1 *}$, Nitin Bhimrao Bavdekar ${ }^{2}$, \\ Deepika Gurnani ${ }^{1}$, Ayushi Kumari ${ }^{1}$
}

\begin{abstract}
${ }^{1}$ Department of Obstetrics and Gynecology, Sir JJ hospital and Grant medical college, Mumbai, Maharashtra, India ${ }^{2}$ Department of Community Medicine, DPH, PGDHAM, PGDMLS MMHS, Maharshtra, India
\end{abstract}

Received: 28 August 2020

Accepted: 08 October 2020

\section{*Correspondence:}

Dr. Amita Shankarrao Budhewar,

E-mail: amitabudhewar25@gmail.com

Copyright: () the author(s), publisher and licensee Medip Academy. This is an open-access article distributed under the terms of the Creative Commons Attribution Non-Commercial License, which permits unrestricted non-commercial use, distribution, and reproduction in any medium, provided the original work is properly cited.

\begin{abstract}
Background: Active tuberculosis is a multiorgan disease caused by primary infection or as a re-activation of latent tuberculosis. The studies comparing maternal and fetal outcome in antenatal women with extrapulmonary tuberculosis and pulmonary tuberculosis is scanty therefore, in current study we outline and identify the demographic and clinical characteristics of pulmonary tuberculosis and extrapulmonary tuberculosis and comparing fetal and maternal outcome in pulmonary and extrapulmonary tuberculosis. The maternal complications and fetal complications of pulmonary tuberculosis were analysed compare with extra pulmonary tuberculosis.

Methods: This was prospective observational study done in tertiary care centre over a period 1.5 year from January 2019 to June 2020. Institute ethical committee approval was obtained. Pregnant women in the age group of 18-42 years diagnosed with tuberculosis in antenatal period were included in our study for comparing fetal and maternal outcomes. They were evaluated for their symptom including clinical examination, microbiological, radiological and biochemical testing. We excluded those antenatal women with tuberculosis and adequately treated and cured and those women with tuberculosis who did not delivered during study period.

Results: Most common complication associated with pulmonary tuberculosis was intrauterine growth restriction whereas in extrapulmonary preterm labour most common complication. Perinatal outcome worse in extrapulmonary tuberculosis as compared to pulmonary tuberculosis.

Conclusions: Pregnancy with tuberculosis worsen the outcome of both mother and fetus. Our study depicted perinatal outcome is worse in Extrapulmonary TB than pulmonary TB. Atypical presentation of the Extrapulmonary TB may constitute diagnostic and therapeutic challenges thus a high clinical suspicion is needed.
\end{abstract}

Keywords: Antenatal women, Comparative, Extra pulmonary, Fetomaternal outcome, Pulmonary tuberculosis

\section{INTRODUCTION}

About one fourth of world's population is estimated to be infected with tuberculosis. ${ }^{1}$ Active tuberculosis is a multiorgan disease caused by primary infection or as a reactivation of latent tuberculosis. Active tuberculosis might be primary tuberculosis or reactivation tuberculosis. Primary tuberculosis occurs when the immune system is unable to defend against the
Mycobacterium tuberculosis bacterium (MTB) infection. On average 5-10 \% of those infected will develop tuberculosis disease over the course of time. ${ }^{2}$ Pregnancy is immunocompromised state so chances of getting disease are substantially high during this period. Globally it is estimated that 216500 pregnant women have active tuberculosis. Tuberculosis is one of the leading cause of death in women of reproductive age group (15-45 years). ${ }^{3}$ Indirect maternal death now account for $28 \%$ of total 
maternal death out of these $15-35 \%$ deaths were due to tuberculosis. ${ }^{4}$

Pulmonary tuberculosis is highly contagious infection that may disseminate in the initial period after infection. ${ }^{5}$ The proportion of pulmonary tuberculosis and extrapulmonary tuberculosis varies with respect to geographical, social, ethical and economical parameter. ${ }^{6}$

Lung most common site of infection and now extra pulmonary site become more prevalent in antenatal women. In extrapulmonary tuberculosis lymph node, abdomen, brain and spine are site of involvement. It has been seen that there is delay in diagnosis of tuberculosis in pregnancy due to various symptoms with which patients present are many times converging to physiological changes in pregnancy. ${ }^{7}$ Extrapulmonary tuberculosis attributed to atypical presentation, diagnostic difficulties, increasing prevalence and potential to result in hazardous sequelae hence increase in clinical awareness for extrapulmonary tuberculosis is crucial. ${ }^{8}$

Active pulmonary tuberculosis infection in pregnancy associated with small for gestation, spontaneous abortion, preterm labour, low birth weight, intrauterine growth restriction, anaemia, perinatal mortality and maternal mortality. ${ }^{9}$ In recent post mortem analysis of maternal death highlight that infections including tuberculosis, is an important contributor to maternal death in India. ${ }^{10}$ However the studies comparing maternal and fetal outcome in antenatal women with extrapulmonary tuberculosis and pulmonary tuberculosis is scanty therefore, in current study we outline and identify the demographic and clinical characteristics of pulmonary tuberculosis and extrapulmonary tuberculosis. We compared the course of pregnancy, pregnancy outcome and perinatal outcome among antenatal women with extrapulmonary tuberculosis and pulmonary tuberculosis. Thereby, we hope to figure out clinical clues may be determined for better recognition and more effective management of disease.

\section{METHODS}

This was prospective observational study done in tertiary care centre over a period 1.5 year from January 2019 to June 2020. Institute ethical committee approval was obtained. Pregnant women in the age group of 18-42 years diagnosed with tuberculosis in antenatal period were included in our study for comparing fetal and maternal outcomes. They were evaluated for their symptom including clinical examination, microbiological, radiological and biochemical testing. We excluded those antenatal women with tuberculosis and adequately treated and cured and those women with tuberculosis who did not delivered during study period.

Data collected from individual case records included age, parity, time of diagnosis, socioeconomic status, mode of delivery, complication in antenatal period, intrapartum period and postpartum period. The mean birth weight of infant, frequency of small for gestation, NICU admission, neonatal mortality and still birth were noted and perinatal outcome was seen.

\section{Statistical analysis}

After collection of data, it was entered in Microsoft excel sheet and analysis was done using SPSS (statistical package of social sciences) version 20 and Epilnfo version 7.2.1. Data is represented in frequencies and mean SD. Chi square test used to check association.

The research is in accordance with ethical guidelines of the institute's ethical committee. Informed consent was taken from the participants involved in this study in the language best known to them.

\section{RESULTS}

\section{Characteristics of the antenatal women with tuberculosis}

In our study, as shown in Table 1 mean age of antenatal women for pulmonary tuberculosis was $22.63 \pm 3.42$ years and for extrapulmonary tuberculosis was $25.32 \pm 1.63$. Majority of women were multigravida in both group.In our study pulmonary tuberculosis 48/60 (80\%) cases belonged to lower socioeconomic status whereas extrapulmonary $15 / 20(75 \%)$ cases belonged to middle socioeconomic status.

Table 1: Characteristics of the antenatal women with tuberculosis.

\begin{tabular}{|lll|}
\hline Characteristics & $\begin{array}{l}\text { Pulmonary } \\
(\mathbf{n}-60)\end{array}$ & $\begin{array}{l}\text { Extrapulmonary } \\
(\mathbf{n}-20)\end{array}$ \\
\hline Age (years) & $22.63 \pm 3.42$ & $25.32 \pm 1.63$ \\
\hline Parity (\%) & $\begin{array}{l}\text { Multi } \\
(66.66 \%)\end{array}$ & Multi $(65 \%)$ \\
\hline $\begin{array}{l}\text { Socioeconomic } \\
\text { status (prasad } \\
\text { scale) }\end{array}$ & $\begin{array}{l}\text { Lower } \\
(80 \%)\end{array}$ & Middle $(75 \%)$ \\
\hline Registration status & $\begin{array}{l}\text { Registered } \\
(83.33 \%)\end{array}$ & $\begin{array}{l}\text { Unregistered } \\
(60 \%)\end{array}$ \\
\hline
\end{tabular}

Table 2: Clinical presentation of pulmonary tuberculosis.

\begin{tabular}{|lll|}
\hline $\begin{array}{l}\text { Clinical } \\
\text { presentation }\end{array}$ & $\begin{array}{l}\text { No of } \\
\text { patients } \\
(\mathbf{n = 6 0 )}\end{array}$ & $\begin{array}{l}\text { Methods of } \\
\text { diagnosis }\end{array}$ \\
\hline $\begin{array}{l}\text { Chronic cough } \\
\text { with } \\
\text { expectoration }\end{array}$ & $\begin{array}{l}50 / 60 \\
(83.33 \%)\end{array}$ & $\begin{array}{l}\text { Sputum AFB, sputum } \\
\text { gene expert }\end{array}$ \\
\hline $\begin{array}{l}\text { Fever, } \\
\text { breathlessness, } \\
\text { haemoptysis }\end{array}$ & $\begin{array}{l}7 / 60 \\
(11.66 \%)\end{array}$ & $\begin{array}{l}\text { Pleural fluid } \\
\text { cytology, tracheal } \\
\text { aspiration gene expert } \\
\text { and cytology }\end{array}$ \\
\hline $\begin{array}{l}\text { Weight loss, } \\
\text { weakness }\end{array}$ & $\begin{array}{l}3 / 60 \\
(5 \%)\end{array}$ & Serial weight scale \\
\hline
\end{tabular}


Table 3: Clinical presentation of extrapulmonary tuberculosis.

\begin{tabular}{|c|c|c|c|}
\hline Site of tuberculosis & Clinical presentation & $\begin{array}{l}\text { No of patients } \\
(n=20)\end{array}$ & Methods of diagnosis \\
\hline $\begin{array}{l}\text { Tubercular lymph- } \\
\text { adenitis }\end{array}$ & Swelling in neck and fever & $10 / 20(50 \%)$ & FNAC of lymph node, USG neck \\
\hline Tubercular meningitis & $\begin{array}{l}\text { Headache, convulsion, } \\
\text { vomiting }\end{array}$ & $4 / 20(20 \%)$ & CSF analysis, MRI brain \\
\hline Abdominal tuberculosis & $\begin{array}{l}\text { Abdominal distension, pain in } \\
\text { abdomen, diarrhoea }\end{array}$ & $4 / 20(20 \%)$ & $\begin{array}{l}\text { Usg guided biopsy, ascitic fluid } \\
\text { cytology, ADA, CT scan }\end{array}$ \\
\hline Potts spine & Back pain, weakness & $1 / 20(5 \%)$ & MRI spine, spinal fluid cytology \\
\hline Renal tuberculosis & $\begin{array}{l}\text { Burning micturition, flank } \\
\text { pain, perinephric abcess }\end{array}$ & $1 / 20(5 \%)$ & $\begin{array}{l}\text { Urine analysis, pus culture } \\
\text { sensitivity and gene expert and renal } \\
\text { biopsy }\end{array}$ \\
\hline
\end{tabular}

As shown in Table 2 Chronic cough with expectoration $(83.33 \%)$ was most common presenting symptom in pulmonary tuberculosis. In extrapulmonary tuberculosis swelling in neck and fever $(50 \%)$ was most common symptom.

\section{Antenatal complication}

As shown in Figure 1 the most common antenatal complication was anaemia $(25 \%)$ in both groups. Apart from this preterm labour (15\%) second most common complication in extrapulmonary tuberculosis whereas intrauterine growth restriction $(8.33 \%)$ was second most common complication in pulmonary tuberculosis.

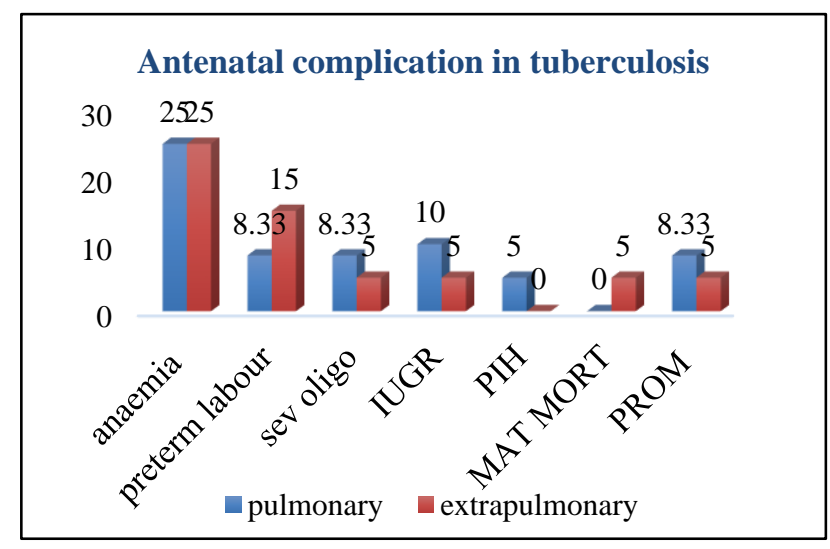

Figure 1: Comparison of antenatal complication in pulmonary and extrapulmonary tuberculosis.

\section{Mode of delivery}

Full term normal vaginal delivery (FTND) was most common mode of delivery in both groups as shown in Figure 2. Preterm vaginal deliveries were more common in extrapulmonary tuberculosis 7 cases $(35 \%)$ as compared to pulmonary tuberculosis 15 cases $(25 \%) .10$ cases (16.66\%) in pulmonary and 2 (10\%) in extrapulmonary tuberculosis were underwent caesarean section with most common indication fetal distress.

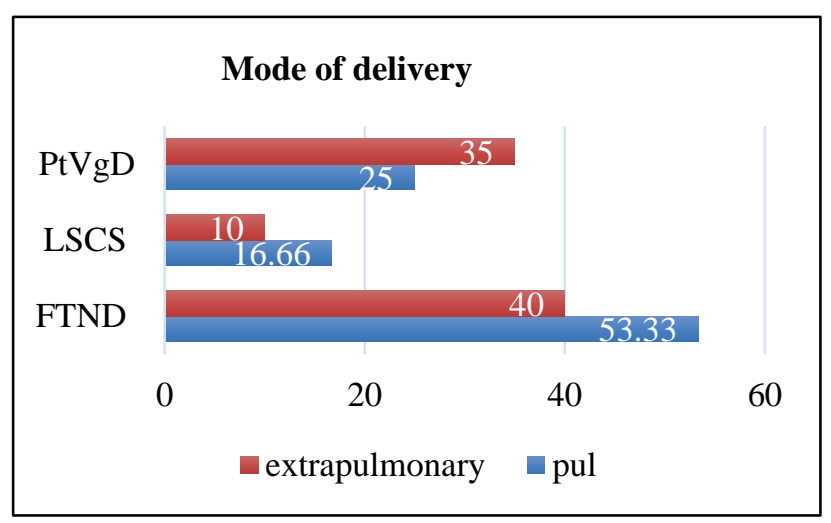

Figure 2: Comparison of pregnancy outcome in pulmonary and extrapulmonary tuberculosis.

\section{Correlation of type of tuberculosis and pregnancy outcome}

Table 4: Correlation of type of tuberculosis and pregnancy outcome.

\begin{tabular}{|lllll|}
\hline \multirow{2}{*}{ Correlation } & \multicolumn{3}{l}{ Group } & \multirow{2}{*}{ Total } \\
\cline { 2 - 5 } & Live & EP & P & \\
\cline { 2 - 5 } Outcome & 12 & 47 & 59 \\
\cline { 2 - 5 } & Abortion & 3 & 1 & 4 \\
\cline { 2 - 5 } & Perinatal mortality & 5 & 11 & 16 \\
\hline & Undelivered & 1 & 0 & 1 \\
\hline Total & & 17 & 58 & 80 \\
\hline
\end{tabular}

There was significant association between adverse pregnancy outcome and extrapulmonary tuberculosis $(\mathrm{p}=0.009)$. Perinatal mortality were seen more in extrapulmonary tuberculosis group with 5 perinatal mortality $(29.41 \%)$ as compared to $9(15.51 \%)$ perinatal mortality in pulmonary tuberculosis as shown in Table 4. Abortion was more in extrapulmonary tuberculosis. 3 $(15 \%)$ had spontaneous abortion in extrapulmonary tuberculosis and $1(1.66 \%)$ in pulmonary tuberculosis. One antenatal woman succumbed in 5 month gestation due to complication of extra pulmonary tuberculosis. 
Table 5: Comparison of fetal outcome in pulmonary and extrapulmonary tuberculosis.

\begin{tabular}{|lll|}
\hline Fetal outcome & $\begin{array}{l}\text { Pulmonary } \\
(\mathbf{n = 4 7 )}\end{array}$ & $\begin{array}{l}\text { Extrapulmonary } \\
(\mathbf{n = 1 2})\end{array}$ \\
\hline Mean birth weight & $2.192 \pm 346$ & $2.375 \pm 682$ \\
\hline SGA & $37(78.72 \%)$ & $8(66.66 \%)$ \\
\hline APGAR $<\mathbf{8}$ & $12(25.53 \%)$ & $8(66.66 \%)$ \\
\hline Respiratory distress & $10(21.27 \%)$ & $3(25 \%)$ \\
\hline NICU admission & $15(31.91 \%)$ & $10(83.33 \%)$ \\
\hline
\end{tabular}

\section{Fetal outcome}

As shown in Table 5 the mean birth weight was $2.192 \pm 346 \mathrm{~kg}$ for pulmonary tuberculosis whereas $2.375 \pm 682 \mathrm{~kg}$ for extrapulmonary tuberculosis. There were more number of small for gestational age (SGA) babies in patient with pulmonary tuberculosis $(78.72 \%)$ as compared to extrapulmonary tuberculosis $(66.66 \%) .{ }^{10}$ $(16.96 \%)$ babies required respiratory support due to prematurity but later 3 babies given to mother in stable condition and were healthy on discharge whereas in extrapulmonary tuberculosis, $3(17.64 \%)$ babies required respiratory support due to prematurity but 2 babies died. There was no case of congenital tuberculosis observed.

Table 6: Comparison of maternal mortality in pulmonary and extrapulmonary tuberculosis.

\begin{tabular}{|lll|}
\hline $\begin{array}{l}\text { Maternal death in cases } \\
\text { of tuberculosis }\end{array}$ & Frequency & $\begin{array}{l}\text { Percentage } \\
(\boldsymbol{\%})\end{array}$ \\
\hline Pulmonary & 10 & 16.66 \\
\hline Extrapulmonary & 3 & 15 \\
\hline Total & 13 & 31.66 \\
\hline
\end{tabular}

\section{Maternal mortality}

As shown in Table 6 maternal mortality due to pulmonary tuberculosis and its complication was 10 cases $(16.66 \%)$ whereas in maternal mortality due to extrapulmonary tuberculosis and its complication was 3 cases $(15 \%)$.

\section{DISCUSSION}

In this study, we aimed to investigate and compare the demographic, clinical, obstetrics and fetal outcome of extrapulmonary and pulmonary tuberculosis. In our study pulmonary tuberculosis more common than extrapulmonary tuberculosis. In our study, 60/80 (75\%) were diagnosed with pulmonary tuberculosis and 20/80 $(25 \%)$ were diagnosed with extrapulmonary tuberculosis as compared to $38 \%$ of pulmonary and $62 \%$ of extrapulmonary cases seen in study conducted by Chopra et al and in Tripathi study cases of pulmonary tuberculosis were $90.88 \%$ and extrapulmonary cases were $9.12 \% .^{11,12}$ In our study average age index $25.63 \pm 3.42$ years in pulmonary and $25.32 \pm 1.63$ years in extrapulmonary tuberculosis which is comparable to
$25.7 \pm 4.22$ years and $28.7 \pm 3.9$ years in study conducted by Chopra et al and Yadav et al respectively. ${ }^{11,13}$

In our study, $48(80 \%)$ women were of lower socioeconomic status in pulmonary tuberculosis whereas in extrapulmonary tuberculosis $15(75 \%)$ antenatal women belonged to middle socioeconomic status. According to Muniyandi's study prevalence tuberculosis higher in those who are living below poverty line. ${ }^{14}$

In our study pulmonary tuberculosis was more prevalent. In extrapulmonary tuberculosis sites of distribution were as follow lymph node (11.25\%), meninges (6.25\%), abdominal (5\%), spinal and renal (1.25\%). Similar distribution seen in Chopra et al study whereas according to Yadav et al study in extra pulmonary tuberculosis genital tuberculosis was the most common site. ${ }^{11,13}$

The effect of tuberculosis depends on various factors such as severity of disease, site of tuberculosis, time of gestation at the time of diagnosis, treatment and compliance to treatment. ${ }^{15}$ Tuberculosis in pregnancy associated with complication like small for gestation, IUGR, preterm labour, spontaneous abortion, low birth weight and increase in neonatal mortality. ${ }^{9}$ In present study anaemia was the most common complication in both groups. Apart from this preterm labour (15\%) second most common complication in extrapulmonary tuberculosis whereas intrauterine growth restriction $(8.33 \%)$ was second most common complication in pulmonary tuberculosis.

According to Mahendru et al tuberculosis associated with low birth weight, poor Apgar score and neonatal mortality similar result seen in our study. ${ }^{16}$ Perinatal morbidity was similar in pregnant women receiving anti tuberculous drugs from early pregnancy to that uninfected women. Tuberculosis associated with pregnancy is an important risk factor for adverse neonatal outcome. ${ }^{17}$ In our study, we found an increased risk of NICU admission, small for gestational age and perinatal mortality in pregnant women with extrapulmonary tuberculosis. The mean birth weight in pulmonary tuberculosis was $2.192 \pm 346 \mathrm{kgs}$ and $2.375 \pm 682 \mathrm{kgs}$ in extrapulmonary tuberculosis. Our study contributes robust evidence suggesting that extrapulmonary tuberculosis has adverse effect on pregnancy outcome and perinatal outcome. In our study 13 maternal mortality were reported; 10 maternal mortality due to pulmonary tuberculosis and its complication and 3 maternal mortality due to extrapulmonary tuberculosis and its complication.

\section{CONCLUSION}

India is the highest Tuberculosis burdened country as per WHO statistics. Pregnancy with tuberculosis worsen the outcome of both mother and fetus. Our study depicted perinatal outcome is worse in extrapulmonary TB than pulmonary TB. Atypical presentation of the 
extrapulmonary TB may constitute diagnostic and therapeutic challenges thus a high clinical suspicion is needed.

\section{Recommendations}

Perinatal tuberculosis difficult to diagnose and can be fatal. All neonates born to tuberculosis mother should be screened for tuberculosis and placenta should be studied for evidence of tuberculosis. Recently, the W.H.O. recommends that "In settings where the tuberculosis prevalence in the general population is $100 / 100000$ population or higher, systematic screening for active TB should be considered for pregnant women as part of antenatal care. Pre conceptional counselling and early antenatal visits are important opportunities to screen and diagnose TB early in its coarse and ensure adequate treatment as per national programme. This will optimize the maternal and perinatal outcome.

\section{Funding: No funding sources}

Conflict of interest: None declared

Ethical approval: The study was approved by the Institutional Ethics Committee

\section{REFERENCES}

1. World Health Organization. WHO consolidated guidelines on tuberculosis: tuberculosis preventive treatment: module 1: prevention: tuberculosis preventive treatment. 2020. Available at https://www.who.int/publications/i/item/whoconsolidated-guidelines-on-tuberculosis-module-1prevention-tuberculosis-preventive-treatment. Accessed on 12 July 2020.

2. Jilani TN, Avula A, Gondal AZ, Siddiqui AH. Active Tuberculosis. In Stat Pearls. Available at https://www.ncbi.nlm.nih.gov/books/NBK441916/ Accessed on 12 July 2020.

3. Say L, Chou D, Gemmill A, Tunçalp Ö, Moller AB, Daniels J, et al. Global causes of maternal death: a WHO systematic analysis. Lancet Glob Health. 2014;2(6):323-33.

4. Sobhy S, Babiker ZO, Zamora J, Khan KS, Kunst H. Maternal and perinatal mortality and morbidity associated with tuberculosis during pregnancy and the postpartum period: a systematic review and metaanalysis. Int J Obst Gynaecol. 2017;124(5):727-33.

5. Glaziou P, Floyd K, Korenromp EL, Sismanidis C, Bierrenbach AL, Williams BG, et al. Lives saved by tuberculosis control and prospects for achieving the 2015 global target for reducing tuberculosis mortality. Bulletin World Health Organization. 2011;89:573-82.

6. Antony SJ, Harrell V, Christie JD, Adams HG, Rumley RL. Clinical differences between pulmonary and extrapulmonary tuberculosis: a 5-year retrospective study. J National Med Asso. 1995;87(3):187.

7. Rezai S, LoBue S, Adams D, Oladipo Y, Posso R, Mapp $\mathrm{T}$, et al. Untreated active tuberculosis in pregnancy with intraocular dissemination: a case report and review of the literature. Case reports Pulmonol. 2015;2015.

8. Sreeramareddy CT, Panduru KV, Verma SC, Joshi HS, Bates MN. Comparison of pulmonary and extrapulmonary tuberculosis in Nepal-a hospitalbased retrospective study. BMC Infect Dis. 2008;8(1):8.

9. Loto OM, Awowole I. Tuberculosis in pregnancy: a review. J Pregnancy. 2012;2012:379271.

10. Panchabhai TS, Patil PD, Shah DR, Joshi AS. An autopsy study of maternal mortality: a tertiary healthcare perspective. J Postgraduate Med. 2009;55(1):8.

11. Chopra S, Siwatch S, Aggarwal N, Sikka P, Suri V. Pregnancy outcomes in women with tuberculosis: a 10-year experience from an Indian tertiary care hospital. Tropical Doc. 2017;47(2):104-9.

12. Tripathy SN, Tripathy AN. Tuberculosis and pregnancy. Int J Gynecol Obst. 2003;80(3):247-53.

13. Yadav V, Sharma JB, Kachhawa G, Kulshrestha V, Mahey R, Kumari R, et al. Obstetrical and perinatal outcome in pregnant women with extrapulmonary tuberculosis. Indian J Tuberculosis. 2019;66(1):15862.

14. Muniyandi M, Ramachandran R, Gopi PG, Chandrasekaran V, Subramani R, Sadacharam K, et al. The prevalence of tuberculosis in different economic strata: a community survey from South India. Int J Tuberculosis Lung Dis. 2007;11(9):10425 .

15. Jana N, Barik S, Arora N, Singh AK. Tuberculosis in pregnancy: the challenges for South Asian countries. J Obst Gynaecol Res. 2012;38(9):1125-36.

16. Mahendru A, Gajjar K, Eddy J. Diagnosis and management of tuberculosis in pregnancy. Obst Gynaecol. 2010;12(3):163-71.

17. LaCourse SM, Greene SA, Dawson EE, Hawes SE. Risk of adverse infant outcomes associated with maternal tuberculosis in a low burden setting: a population-based retrospective cohort study. Infect Dis Obst Gynecol. 2016;2016: 6413713.

18. WHO recommendations on antenatal care for a positive pregnancy experience. Geneva: World Health Organization; 2016.

Cite this article as: Lewis PF, Budhewar AS, Bavdekar NB, Gurnani D, Kumari A. Comparative analysis of fetomaternal outcome in antenatal women infected with pulmonary and extrapulmonary tuberculosis. Int J Reprod Contracept Obstet Gynecol 2020;9:4580-4. 